\title{
CORPUS Corpus
}

Archivos virtuales de la alteridad americana

Vol. 8, No 1 | 2018

Enero / Junio 2018

\section{Por una teología política de 1918}

\section{Guillermo Vázquez}

\section{(2) OpenEdition}

\section{Journals}

Electronic version

URL: http://journals.openedition.org/corpusarchivos/2236

DOI: 10.4000/corpusarchivos.2236

ISSN: 1853-8037

\section{Publisher}

Diego Escolar

\section{Electronic reference}

Guillermo Vázquez, «Por una teología política de 1918 », Corpus [En línea], Vol. 8, No 1 | 2018,

Publicado el 29 junio 2018, consultado el 02 mayo 2019. URL : http://journals.openedition.org/ corpusarchivos/2236 ; DOI : 10.4000/corpusarchivos.2236

This text was automatically generated on 2 May 2019.

Licencia Creative Commons: Atribución-NoComercial 2.5 Argentina (CC BY-NC 2.5 AR) 


\title{
Por una teología política de 1918
}

\author{
Guillermo Vázquez
}

\section{Uno}

1 En 1922, Carl Schmitt escribe la primera conceptualización sistemática ${ }^{1}$ remarcando la presencia del lenguaje teológico secularizado en la Teoría del Estado. Cómo la tradición moderna, presuntamente vencedora del Ancién Regime de las Sagradas Escrituras, seguía en la órbita conceptual de lo teológico-político. Acá nos mueve un interés similar: cómo es que prevalece en muchos aspectos esa traslación en los jóvenes reformistas y sus derivas posteriores.

2 En la historia del laicismo argentino, la Reforma de 1918 constituye sin duda alguna uno de sus capítulos más contundentes. Tanto por el antagonista de su movilización -ese entramado monárquico y monástico de un círculo docente y social del catolicismo cordobés-, como por las reivindicaciones de toda su generación, que amalgaman corpus teóricos específicos como apuestas políticas e institucionales de relevancia en ese sentido. Recorre en los reformistas (allí los estudios de Diego Tatián 2016) una suerte de afán spinozista del Tratado Teológico-Político por poner en su lugar las pretensiones salvíficas y antimaterialistas de la historia y la filosofía ultrateologizada que por entonces conformaban planes de estudios y prácticas políticas de la elite dirigente. ${ }^{2} \mathrm{~A}$ su vez, el diario Los Principios, principal órgano de la oposición a los reformistas, sostendrá un lenguaje katejóntico -sin faltar las clásicas tesis conspiracionistas que involucraban masonería y "sinarquía internacional" detrás del plan reformista-, muy marcado por la discursividad evangélica, para señalar lo que estaba en juego en aquella disputa: los satánicos estudiantes se disponían a derribar la última barrera para la venida del Anticristo. Es lo que varios años después, el donosiano argentino Alberto Caturelli haciendo un intento por leer la filosofía cordobesa- ve en aquel movimiento y sus referentes.

3 En el año 1884, con motivo de la tesis de Ramón J. Cárcano "De los hijos adulterinos, incestuosos y sacrílegos" -innegable antecedentes de 1918-, las calles de Córdoba habían visto ya una disposición a la conflagración donde los símbolos religiosos (en este caso, 
bajo la forma de una procesión comandada por el obispado cordobés) tomaban centralidad. Si en aquel entonces el catolicismo local las había ocupado con sus vírgenes y cruces, en 1918 los reformistas ganarán esas mismas calles, con el tono absolutamente inverso, quemando cuadros de frailes, volteando estatuas de obispos, etc.

Y sin embargo...

\section{Dos}

5 El miércoles 17 de junio de 2015, como todos los años desde hace una centuria, la Universidad Nacional de Córdoba organizó una mesa en la sala del Consejo Superior para conmemorar otro aniversario de la Reforma Universitaria. Entre los panelistas, se encontraba un gran militante del Peronismo de Base de la década del 70, Luis "Vitín" Baronetto, cuya alocución (además de inspirar estas notas) marcó un eje posible para repensar la Reforma a contrapelo de la corrección política y el aletargamiento en que el acontecimiento del 18 venía celebrándose. Provocadoras, a la vez que sinceras y agudas, las notas de Baronetto comenzaron tomando algunas frases del Manifiesto Liminar -cuya hondura de fuentes y la misma idea del redactor colectivo no se han explorado lo suficiente-: "Córdoba se redime", el "derecho sagrado a la insurrección", la "santa revolución", las "almas de los jóvenes deben ser movidas por fuerzas espirituales" y algunas otras de célebres reformistas. Un anticlericalismo que no dejaba de ser inspirado por una cierta religiosidad. Dijo allí Vitín que el uso de metáforas religiosas en los jóvenes reformistas le recordó lo que sucedía en su militancia en barrios populares de Córdoba, a fines de los 60 y principios de los 70: una suerte de sincretismo entre la palabra del Evangelio y la arenga revolucionaria al interior del peronismo, una indiferenciación -por momentos- entre parroquia y unidad básica, lugares ambos donde se transitaban los mismos objetivos. Todo dentro de un esquema discursivo de la época donde la palabra evangélica se mostraba plenamente imbricada a la transformación social que se intentaba ( $s i n$ necesidad de referir a ningún sacerdote tercemundista, o a la mítica revista Cristianismo y Revolución, pensemos por caso en la retórica de Raimundo Ongaro).

Una forma de teología política que tomaba de las metáforas religiosas una fuerza sin renunciar al liberalismo que la movía. El punto de llegada de esa invisible e inexplorada conexión entre tradiciones diversas (por caso, la que propone Vitín, ese puente nunca directo ni de asfalto fuerte entre el 18 y la Juventud Peronista de la Resistencia) puede ser interesante para remover el legado de cierta corrección laica al retomar las conmemoraciones de la Reforma, y pensar cruces y destinos posibles que nunca son uniformes.

7 Si hay cierto sarcasmo en el Manifiesto sobre la "religión de esclavos" -la influencia de las lecturas de Nietzsche en la Reforma comienza a estudiarse de a poco, pero es una de las fuentes de primera o segunda mano de mucha relevancia-, parece ir por el lado de la crítica a la religión como un mandato ortodoxo que frena transformaciones sociales, el rechazo a la identificación del legado de Cristo con el legado monástico que hacía de Córdoba la referencia católica del país. 


\section{Tres}

8 El gran estudio preliminar y compilación de Marcelo Padoan Jesús, el templo y los viles mercaderes. Un examen de la discursividad yrigoyenista (UNQ 2002), marca un importante hito en lo que aquí exponemos. Para el movimiento yrigoyenista, el líder radical era un Apóstol, un nuevo Jesús de la política argentina, alguien enviado por la Providencia para correr del templo (la patria) a los mercaderes. Asimismo, para una parte importante de la oposición a Yrigoyen, la disputa se daba en el mismo campo semántico, y aquel líder era en realidad un falso apóstol, un mesías engañoso que reproducía la tiranía rosista. El clásico texto de Arturo Roig, Los krausistas argentinos, había dado en su momento algunas explicaciones a esta retórica religiosa en el campo político argentino posterior a la ley Sáenz Peña, a partir del lugar en el cual el krausismo había puesto a Jesús -sobre todo en el texto del filósofo alemán Ideal de la humanidad para la vida-, asociándolo a una "religión del amor".

9 En los reformistas, creemos, este lenguaje de respeto por la figura de Cristo y un uso civil de la metáfora evangélica es similar, si bien no asociada a la figura de ningún liderazgo mesiánico como en el yrigoyenismo (o, para otro caso, ver el libro de Mariano Ben Plotkin Mañana es San Perón). La Gaceta Universitaria, el periódico estudiantil, utilizará símiles de estas metáforas plétoras en la discursividad yrigoyenista: la parábola del buen samaritano asimilado a la solidaridad obrera en un texto de Lelio Zeno, ${ }^{3}$ o "Los carnerosfariseos y el doctor Martínez"4 en la discusión inmediatamente posterior a junio del 18.

En un libro titulado La preocupación religiosa de los hombres de Mayo, Daniel P. Monti comienza con una observación de Esteban Echeverría sobre el olvido y la desatención del sentimiento religioso en la política argentina en general, y en la campaña de los referentes de Mayo en particular. Para contrarrestar la observación del autor de la Generación del 37, Monti toma algunos textos -el milenarismo del jesuita chileno Manuel Lacunza o el "protestantismo autóctono" de Francisco Ramos Mejía son ejemplos de autores bien considerados por la generación de Mayo- y episodios de relativa influencia en la Revolución de 1810 y sus referentes políticos en los cuales hay un sentimiento religioso, o una lectura religiosa de la historia buscando a su vez conservar el carácter "liberal".

11 En el año 1906, uno de los maestros y fuente inspiradora del movimiento cordobés del 18, el uruguayo José Enrique Rodó había marcado su desacuerdo con la decisión de la Comisión de Caridad y Beneficencia Pública de retirar los crucifijos de las paredes del Hospital de Caridad. Lo relevante es que no lo hizo bajo la admonición religiosa de alguien herido en su fe, cual sacrilegio. Escribió que lo hizo desde una posición de admiración "puramente humana" por la figura de Cristo y su vinculación con la caridad, argumentando que era lo mismo que en Argentina se retiraran los cuadros de San Martín y Belgrano: Cristo pasaba a ser una figura laica vinculada histórica y filosóficamente al concepto de caridad. Rodó sostenía una "adhesión racional a los fundamentos de una doctrina que tengo por la más verdadera y excelsa concepción del espíritu del hombre" (Rodó 1956:200). Para el uruguayo, aquel había sido un acto de jacobinismo, no de liberalismo. Diferencia que, sospechamos, no sería del todo del agrado de los reformistas, aunque en su respuesta a la polémica que desató su intervención en el liberalismo uruguayo de comienzos del siglo XX, expuso lo siguiente, en sintonía con muchas de las posiciones reformistas: 
(...) las organizaciones seudoliberales que entrañan la guerra incondicional y ciega contra determinada fe religiosa, excluyendo la posibilidad de diferenciar, de discernir, de hacer las salvedades y excepciones que la justicia exija, en cuanto a la tradición histórica o en cuanto a las manifestaciones actuales de esa fe -vale decir, excluyendo la posibilidad de un ejercicio leal e independiente del criterio personal-, son en sí mismas una persistente negación del pensamiento libre. ${ }^{5}$

Continúa, reafirmando lo que él cree que es una verdadera posición liberal:

(...) el pensamiento libre (...), abarca mucho más e implica algo mucho más alto que una siempre obsesión antirreligiosa; y el procedimiento con que puede tenderse eficientemente a su triunfo es, lo repito, el de la educación atinada y metódica, perseverante y segura, que nada tiene que ver con organizaciones sistemáticas conducentes a sustituir un fanatismo con otro fanatismo; la autoridad irracional de un doga con la autoridad irracional de una sugestión de prejuicios; el amor ciego de una fe con el odio ciego de una incredulidad. ${ }^{6}$

Otra defensa laica del legado de Cristo puede verse en La Universidad Nueva de Alfredo Palacios, en torno a los programas de Filosofía donde el cristianismo comienza a leerse por fuera del dogma católico que lo animaba.

14 Al final de su vida, Enrique Barros llevaba en el bolsillo de su chaleco una nota que decía: "Yo, Enrique Barros, en pleno uso de mis facultades mentales y sabiéndome aquejado de una dolencia que en cualquier momento puede hacer crisis, prohíbo que en tal caso, ni vivo ni muerto, llegue hasta mí un sacerdote de la religión católica apostólica romana, a la que considero la negación de la doctrina de Cristo". Seguramente atendiendo al riesgo de que se repitiera lo lo que el diario Los Principios, con gran cinismo, había hecho con la necrológica de Deodoro Roca en 1942: decía que había clamado por un sacerdote en sus últimas horas, muriendo confortado por la religión.7 Zizek ha afirmado -con su usual provocación, aunque con una argumentación atendible que no detallaremos aquí- que solo un ateo puede ser un verdadero cristiano.

Cuatro

Es común volver a la observación de Aricó, como una deuda que se busca saldar de alguna manera en partes: la necesidad de reconstrucción de los sucesos de 1918 más allá de sus causalidades evidentes, y buscar en cambio aquellas que permanecen aún bajo cierta sombra (ya menos que en el momento en que Aricó lo afirmaba, seguramente) en relación a la "trama viva de los nexos intelectuales que le dieron voz, de manera súbita y acabada, a una filosofía convertida en práctica". Creemos entonces que el vitalismo de aquella voz, o de aquellas voces, debe explorarse también por la vía teológico-política: la secularización de conceptos religiosos que los reformistas producen; sus relecturas laicas del Evangelio y la cristología como enclaves de la justicia mundana que reclamaban; el uso de metáforas y parábolas bíblicas como mitos fundantes de emprendimientos emancipadores; como así también la búsqueda de una "religión civil" à la Rousseau que garantizase el compromiso virtuoso con lo que se había iniciado en la irrupción violenta y convencida de un conjunto de jóvenes en un salón pretendidamente aristocrático de la calle Obispo Trejo. 


\section{BIBLIOGRAPHY}

Tatián, D. (2016). “León Dujovne, la paciencia de la obra”. En L. Dujovne, Spinoza: su vida, su época, su obra (2 tomos). Buenos Aires: Biblioteca Nacional.

Rodó, J. E. (1956). “Liberalismo y jacobinismo”. En Obras Selectas. Buenos Aires: El Ateneo.

\section{NOTES}

1. Hablamos, claro, de Teología política. Si bien había otras anteriormente, que arribaban por otros lugares y destinos ideológicos bien distintos de las conclusiones schmittianas: por ejemplo la de Kelsen “Dios y Estado”, y el bien anterior y clásico, Dios y el Estado de Bakunin.

2. En el mismo sentido, aunque con una lectura no tan crítica de la teología histórica cristiana, el libro de Carlos Astrada El marxismo y las escatologías (Procyon, Buenos Aires, 1957) es uno de los puntos más altos de esta discusión.

3. Cfr. la edición facsimilar de La Gaceta Universitaria 1918-1919, UNC, UNLP, UNL, UNT, UBA, Buenos Aires, 2008, p. 214.

4. Cfr. la edición facsimilar de La Gaceta Universitaria 1918-1919, UNC, UNLP, UNL, UNT, UBA, Buenos Aires, 2008, p. 145.

5. Cfr. la edición facsimilar de La Gaceta Universitaria 1918-1919, UNC, UNLP, UNL, UNT, UBA, Buenos Aires, 2008, p. 257.

6. Cfr. la edición facsimilar de La Gaceta Universitaria 1918-1919, UNC, UNLP, UNL, UNT, UBA, Buenos Aires, 2008, p. 259.

7. Le pasó a Fidel Castro hace poco tiempo, bajo uno de los titulares tenebrosos y arteros del diario Clarín: “Aseguran que Fidel Castro murió confortado por la religión". Cfr. https:// www.clarin.com/mundo/aseguran-fidel-castro-murio-confortado-religion_0_By2N5bjhl.html

\section{AUTHOR}

\section{GUILLERMO VÁZQUEZ}

Facultad de Filosofía y Humanidades y Facultad de Ciencias Sociales, Universidad Nacional de Córdoba, Argentina 